\title{
Brain and intersubjectivity: a Hegelian hypothesis on the self-other neurodynamics
}

\section{Igor Marchetti * and Ernst H. W. Koster}

Department of Experimental-Clinical and Health Psychology, Ghent University, Ghent, Belgium

*Correspondence: igor.marchetti@ugent.be

Edited by:

Leonhard Schilbach, University Hospital Cologne, Germany

Reviewed by:

Guillaume Dumas, Florida Atlantic University, USA

Keywords: intersubjectivity, self-consciousness, default mode network, mirror neuron system, self concept, dehumanization, Hegel

\section{INTRODUCTION}

Human beings live in a social context, where interacting with others is crucial for survival, and having a clear representation of both the "self" and the "other" is needed (Baumeister, 2011). Interestingly, neuroscience has traditionally adopted a Cartesian perspective by which the self is a solipsistic and self-sufficient unit, fundamentally unrelated to the other individuals' representation. Since the last decade, however, neuroscience is increasingly promoting research about how the "self" and the "other" are processed and represented at both intra- (Decety and Sommerville, 2003; Denny et al., 2012; Wagner et al., 2012; Molnar-Szakacs and Uddin, 2013) and inter-brain level (Dumas et al., 2010, 2012). Nevertheless, the specific way whereby neural self-other representations co-occur and exert influence on each other in order to promote higher-order functions necessary for social functioning remains largely unclear. We propose that the philosophical theory of intersubjectivity (Hegel, 1807/1977) could integrate neuroscience findings and, in turn, shed new light on the self-other dynamics at neurocognitive level.

\section{HEGEL AND SELF-OTHER DYNAMICS}

Philosophy has intensively studied the interaction between the self and other, terming sometimes their interplay as intersubjectivity. In 1807, the German philosopher, Georg Wilhelm Friedrich Hegel, published the Phenomenology of Spirit (Hegel, 1807/1977), where he thoroughly investigated the progressive steps that from a relatively simple form of thinking, such as consciousness, lead to higher-order functions, such as self-consciousness.
According to Hegel, consciousness is the mental function that accounts for ordered experience and which provides us with a unified experience of reality, instead of a chaotic flow of meaningless information. By means of consciousness, we are therefore able to represent and process in a meaningful way the stimuli that fall in our phenomenal space. Recent theoretical efforts have associated this crucial mental function with specific brain dynamics: rest-stimulus interaction at the level of cortical and subcortical midline regions (Northoff, 2012).

Compared with earlier philosophers, Hegel took the notion of consciousness one step further. In line with his idealistic assumptions, he proposes that the mind actively "constructs" the objects of our knowledge, with no need for the latter to rely on cognitively inaccessible external entities. Earlier thinkers, such as Immanuel Kant, had indeed argued that these founding external entities were not comprehensible to our mind (i.e., thing-in-itself or noumenon) (Kain, 2005). Although his theory probably qualifies Hegel as one of the first radical constructivists, it also raises a fundamental question. If neither based on external reality nor on itself, on what is our selfconsciousness based? Hegel (1807/1977) clearly answers that "Self-consciousness exists in and for itself when, and by the fact that, it so exists for another; that is, it exists only in being acknowledged" (paragraph 178) (Hegel, 1807/1977). Three elements are noteworthy here. First, Hegel proposes a condition of necessity in the self-other dyad, with each pole needing to be recognized by the other one (i.e., mutual recognition or intersubjectivity). Second, both the self and the other maintain their specific identity without merging into an undifferentiated matrix (Coelho and Figueiredo, 2003), in that the other is recognized as a separate subjectivity with whom a shared subjective state is possible (i.e., recognition of the other). Third, the self, at least in part, exists insofar as being constructed by the other that recognizes it back (i.e., recognition of the self). Without the other, the self lacks a fundamental reference to contrast itself with, and, in turn, it is bound not to emerge in the biological and psychological context (Baumeister, 2011). Importantly, a simple object fundamentally lacks selfconsciousness and as such it is not eligible to recognize one's self as this would lead the latter to become " a motionless tautology of I am I" (paragraph 167) (Hegel, 1807/1977). In other words, if the other's recognition is lacking, I can experience events and objects (i.e., consciousness), but I cannot experience myself as a selfconscious agent (i.e., self-consciousness).

From the intersubjective perspective, the "other" is necessary. Not only must the other be physically present with its own body (Mead, 1934/2009; Russon, 1997), but the other must also recognize the subject as an intentional and self-conscious self (Kain, 2005). In order to process such fundamental but complex input, the brain is expected to be properly equipped to detect recognition by others.

\section{INTERSUBJECTIVITY, DEFAULT MODE NETWORK, AND MIRROR NEURON SYSTEM}

How may Hegelian intersubjectivity inform our knowledge of the brain and, in turn, account for our social functioning? Intersubjectivity could shed light on 
recent neuroimaging findings by integrating two of the most active research lines in neuroscience, the Mirror Neurons System (MNS) and the Default Mode Network (DMN).

In the social context, the perception of a meaningful and goal-directed action leads to specific neural activation, regardless whether the action is performed by the subject itself or it is observed being performed by another actor (Iacoboni et al., 1999). The MNS has indeed been consistently associated with this function whereby the other's instrumental behavior is neuronally represented in the observer by means of a motor resonance mechanism. In other words, a significant gesture is encoded also in the observer's brain within its own motor schemata and this helps qualify the person of the observer as a (potentially) active and goal-directed actor. On the contrary, immobile objects or aimless actions do not elicit a similar response in the MNS (Preston and de Waal, 2002). Interestingly, already in the 1930's George Herbert Mead, a sociologist deeply influenced by Hegel's theory, stressed the importance of this "conversation of gestures" between individuals as the first step leading to higher levels of self-consciousness (Mead, 1934/2009; Markova, 1990). The MNS can therefore be considered as a neural tool that bridges the gap between the self and the other at the level of lower-order physical representation (Rizzolatti and Sinigaglia, 2010).

The DMN, a neural network highly active during rest, has been associated with psychological representing of others, that is mentalizing (Van Overwalle and Baetens, 2009; Schilbach et al., 2012). This cognitive ability to adopt someone else's perspective and internally represent mental states of others (i.e., beliefs, intentions, and goals) implies that we subsume the cognitive representation of other's mental activity into ours to some extent. Interestingly, while the MNS relies on the perception of other's embodied actions, mentalizing requires the ability to extract and understand goals and intentions of others. The latter implies that the other is recognized as an agent. Therefore, the DMN seems to subserve the mechanism through which the other psychologically resonates into one's mind as an intentional being (Molnar-Szakacs and Uddin, 2013).
As intersubjectivity is emerging as a promising perspective in neuroscience (Allen and Williams, 2011), we contend that it can meaningfully integrate these findings. Our Hegelian model suggests that it is the long-term interaction between the pre-reflective "I" (i.e., consciousness) and the other's representation, both at physical (Mead, 1934/2009; Russon, 1997) and psychological (Kain, 2005) level, that gives rise to a self-reflective " $I$ " (i.e., selfconsciousness). Hence, a self-conscious individual is capable not only of processing internal/external stimuli, but also of actively reflecting upon herself, which creates a network of information related to the self, such as attributes, beliefs, and traits (Baumeister, 2011).

In neurocognitive terms, we could say that self-awareness is the product of interactions between both lower- and higherorder functions, such as motor resonance and mentalizing subserved by the MNS and DMN, respectively. Crucially, this neural cooperation has been recently confirmed by a meta-analysis showing that self-specific activity emerges as interaction between the DMN (i.e., perigenual anterior cingulate cortex [pACC] and posterior cingulate cortex [PCC]), and MNS (i.e., left anterior insula [1AI] and right inferior frontal gyrus [rIFG]) (Qin and Northoff, 2011). Moreover, mentalizing about the self and other is associated with similar neurocircuitry, yet, the brain seems to be capable of distinguishing between them without equating one to the other (Lombardo et al., 2010).

In sum, Hegel's model of mutual recognition converges with neuroscience findings in that in order to understand ourselves we must rely on the same mechanisms that we use for understanding others. Self and other representations are strictly bond without one dissolving into the other (Coelho and Figueiredo, 2003; Lombardo et al., 2010). Notwithstanding this, the representation of others' minds and actions shapes our own mind, as both motor resonance mechanism (i.e., MNS) and mentalizing (i.e., DMN) are necessary to support and maintain the selfreflective self (Lombardo et al., 2010; Qin and Northoff, 2011; Sandrone, 2013). It is noteworthy that a similar hypothesis has been recently proposed by Timmermans et al. (2012). The authors propose that a set of neurobiological prediction-based mechanisms support our constant attempt to model other's mind and the related social interaction. Importantly, the very same mechanism is proposed to be crucial for developing self-consciousness too.

\section{THE MASTER-SLAVE DYNAMIC IN THE BRAIN}

Representation of the self and other is associated to a large extent with the same neural circuitry (Lombardo et al., 2010), and mutual recognition of self and other is required (Hegel, 1807/1977; Kain, 2005). However, this double bind implies a fragile equilibrium between the two components of the dyad. What if, for instance, the self fails to recognize the other? What if mutual recognition is deficient (Williams, 1997)?

Hegel (1807/1977) addresses this point by introducing the famous literary example of the master-slave dynamic, as follows. Given a couple of peers, one of the two could desire to undermine equilibrium by overpowering the other. Hence, one would become the "master" while the other becomes the "slave". However, the situation is bound to turn out paradoxical. By not considering the other a full self-consciousness (i.e., objectification), the master prevents the slave from recognizing it back. Consequently, the master hinders the process of mutual recognition upon which it itself relies in order to emerge as a self-conscious individual. In cognitive terms, we could say that the individual enhances the threshold to receive the recognizing input that could structure it as self-conscious.

From this, several hypotheses derive. First, objectifying the other (i.e., negating its status of human being) leads, to a certain extent, also to a self-objectification, as the source of recognition is now lacking. Second, objectifying the other is expected to impact on the DMN and/or the MSN, the neurobiological systems maintaining self-consciousness. Preliminary findings support these hypotheses. First, being subjected to ostracisim (i.e., seeing the status of human being negated) leads the victims to judge both themselves and the ostracizer(s) less human (Bastian and Haslam, 2010). Second, actively engaging in ostracism makes the ostracizer feel 
less related to human beings (Legate et al., 2013). Third, a recent study showed that inducing participants to consider other human beings as objects leads to decreased activity of the DMN (Jack et al., 2013).

\section{CONCLUDING REMARKS}

Hegel's theory of intersubjectivity seems capable of shedding new light on the complex interaction between the self and the other at both neural and cognitive level. The interplay between the DMN and the MNS in supporting self-awareness may indeed be interpreted fruitfully by reintroducing the concept of mutual recognition.

Importantly, new hypotheses can be derived from the classic work of Hegel in order to better account for the interaction between DMN and MNS in both healthy and clinical samples. For instance, major psychopathologies characterized by abnormal self-other dynamic, such as schizophrenia, autism, and depression (Northoff, 2007; Crespi and Badcock, 2008; Mehta et al., 2012; Billeke et al., 2013; Gallese et al., 2013), represent key areas to test the explanatory power of the intersubjective theory. Finally, our neurophilosophical framework could be fruitfully integrated in a new branch of social neuroscience, namely the two-person neuroscience (Schilbach et al., 2013). By focusing on the neurocognitive basis of the interaction between two individuals, two-person neuroscience is developing new experimental paradigms and innovative methods to analyze real-time two-brain interplay, such as simultaneous neuroimaging recording or, so-called, hyperscanning (Dumas, 2011; Babiloni and Astolfi, in press). In sum, we argue that the integration of our Hegelian neurophilosophical approach and two-person neuroscience holds promise to convey innovative future perspectives in the field of social neuroscience.

\section{ACKNOWLEDGMENTS}

Preparation of this article was supported by a Grant of the Special Research Fund (BOF) of Ghent University (BOF 10/2JO/061) awarded to Ernst Koster. The authors wish to thank Dr. M. Brass for his constructive comments on a previous version of this manuscript.

\section{REFERENCES}

Allen, M., and Williams, G. (2011). Consciousness, plasticity, and connectomics: the role of intersubjectivity in human cognition. Front. Psychol. 2:20. doi: 10.1098/rstb.2011.0417

Babiloni, F., and Astolfi, L. (in press). Social neuroscience and hyperscanning techniques: past, present and future. Neurosci. Biobehav. Rev. doi: 10.1016/j.neubiorev.2012.07.006

Bastian, B., and Haslam, N. (2010). Excluded from humanity: the dehumanizing effects of social ostracism. J. Exp. Soc. Psychol. 46, 107-113. doi: 10.1016/j.jesp.2009.06.022

Baumeister, R. F. (2011). Self and identity: a brief overview of what they are, what they do, and how they work. Ann. N.Y. Acad. Sci. 1234, 48-55. doi: 10.1111/j.1749-6632.2011. 06224.x

Billeke, P., Boardman, S., and Doraiswamy, P. M. (2013). Social cognition in major depressive disorder: a new paradigm? Transl. Neurosci. 4, 437-447. doi: 10.2478/s13380-013-0147-9

Coelho, N. E., and Figueiredo, L. C. (2003). Patterns of intersubjectivity in the constitution of subjectivity: dimensions of otherness. Cult. Psychol. 9, 193-208. doi: 10.1177/1354067x030093002

Crespi, B., and Badcock, C. (2008). Psychosis and autism as diametrical disorders of the social brain. Behav. Brain Sci. 31, 241-26. doi: 10.1017/S0140525X08004214

Decety, J., and Sommerville, J. A. (2003). Shared representations between self and other: a social cognitive neuroscience view. Trends Cogn. Sci. 7 , 527-533. doi: 10.1016/j.tics.2003.10.004

Denny, B. T., Kober, H., Wager, T. D., and Ochsner, K. N. (2012). A meta-analysis of functional neuroimaging studies of self- and other judgments reveals a spatial gradient for mentalizing in medial prefrontal cortex. J. Cogn. Neurosci. 24, 1742-1752. doi: 10.1162/jocn_a_00233

Dumas, G. (2011). Towards a two-body neuroscience. Commun. Integr. Biol. 4, 349-352. doi: 10.4161/cib.4.3.15110

Dumas, G., Martinerie, J., Soussignan, R., and Nadel, J. (2012). Does the brain know who is at the origin of what in an imitative interaction? Front. Hum. Neurosci. 6:128. doi: 10.3389/fnhum.2012.00128

Dumas, G., Nadel, J., Soussignan, R., Martinerie, J., and Garnero, L. (2010). Inter-brain synchronization during social interaction. PLOS ONE 5:e12166. doi: 10.1371/journal.pone.0012166

Gallese, V., Rochat, M. J., and Berchio, C. (2013). The mirror mechanism and its potential role in autism spectrum disorder. Dev. Med. Child Neurol. 55, 15-22. doi: 10.1111/j.1469-8749.2012.04398.x

Hegel, G. W. F. (1807/1977). Phenomenology of Spirit. Transl. A. V. Miller (Oxford: Oxford University Press)

Iacoboni, M., Woods, R. P., Brass, M., Bekkering, H., Mazziotta, J. C., and Rizzolatti, G. (1999). Cortical mechanisms of human imitation. Science 286, 2526-2528. doi: 10.1126/science.286.5449.2526

Jack, A. I., Dawson, A. J., and Norr, M. E. (2013). Seeing human: distinct and overlapping neural signatures associated with two forms of dehumanization. Neuroimage 79, 313-328. doi: 10.1016/j.neuroimage.2013.04.109

Kain, P. J. (2005). Hegel and the Others: a Study of the Phenomenology of Spirit. Albany, NY: State University of New York Press.

Legate, N., DeHaan, C. R., Weinstein, N., and Ryan, R. M. (2013). Hurting you hurts me too: the psychological costs of complying with ostracism. Psychol. Sci. 24, 583-588. doi: 10.1177/0956797612 457951

Lombardo, M. V., Chakrabarti, B., Bullmore, E. T., Wheelwright, S. J., Sadek, S. A., Suckling, J., et al. (2010). Shared neural circuits for mentalizing about the self and others. J. Cogn. Neurosci. 22, 1623-1635. doi: 10.1162/jocn.2009. 21287

Markova, I. (1990). "The development of selfconsciousness: Baldwin, Mead, And Vygotsky," in Reconsidering Psychology: Perspectives from Continental Philosophy, eds J. E. Faulconer and R. N. Williams (Pittsburgh, PS: Duquesne University Press), 151-174.

Mead, G. H. (1934/2009). Mind, Self, and Society: From the Standpoint of a Social Behaviorist. Chicago, Il: University of Chicago Press.

Mehta, U. M., Basavaraju, R., Thirthalli, J., and Gangadhar, B. N. (2012). Mirror neuron dysfunction-a neuro-marker for social cognition deficits in drug naive schizophrenia. Schizophr. Res. 141, 281-283. doi: 10.1016/j.schres.2012. 07.005

Molnar-Szakacs, I., and Uddin, L. Q. (2013). Selfprocessing and the default mode network: interactions with the mirror neuron system. Front. Hum. Neurosci. 7:571. doi: 10.3389/Fnhum.2013. 00571

Northoff, G. (2007). Psychopathology and pathophysiology of the self in depression - neuropsychiatric hypothesis. J. Affect. Disord. 104, 1-14. doi: 10.1016/j.jad.2007.02.012

Northoff, G. (2012). Immanuel Kant's mind and the brain's resting state. Trends Cogn. Sci. 16, 356-359. doi: 10.1016/j.tics.2012.06.001

Preston, S. D., and de Waal, F. B. M. (2002). Empathy: its ultimate and proximate bases. Behav. Brain Sci. 25, 1-20. doi: 10.1017/S0140525X02 000018

Qin, P., and Northoff, G. (2011). How is our self related to midline regions and the defaultmode network? Neuroimage 57, 1221-1233. doi: 10.1016/j.neuroimage.2011.05.028

Rizzolatti, G., and Sinigaglia, C. (2010). The functional role of the parieto-frontal mirror circuit: interpretations and misinterpretations. Nat. Rev. Neurosci. 11, 264-274. doi: 10.1038/ nrn2805

Russon, J. (1997). The Self and its Body in Hegel's Phenomenology of Spirit. Toronto, ON: University of Toronto Press.

Sandrone, S. (2013). Self through the mirror (neurons) and default mode network: what neuroscientists found and what can still be found there. Front. Hum. Neurosci. 7:383. doi: 10.3389/fnhum.2013.00383

Schilbach, L., Bzdok, D., Timmermans, B., Fox, P. T., Laird, A. R., Vogeley, K., et al. (2012). Introspective minds: using ALE meta-analyses to study commonalities in the neural correlates of emotional processing, social \& unconstrained 
cognition. PLoS ONE 7:e30920. doi: 10.1371/journal.pone.0030920

Schilbach, L., Timmermans, B., Reddy, V., Costall, A., Bente, G., Schlicht, T., et al. (2013). Toward a second-person neuroscience. Behav. Brain Sci. 36, 393-414. doi: 10.1017/S0140525X120 00660

Timmermans, B., Schilbach, L., Pasquali, A., and Cleeremans, A. (2012). Higher order thoughts in action: consciousness as an unconscious redescription process. Philos. Trans. R. Soc. B Biol. Sci. 367, 1412-1423. doi: 10.1098/rstb.2011. 0421

Van Overwalle, F., and Baetens, K. (2009). Understanding others' actions and goals by mirror and mentalizing systems: a metaanalysis. Neuroimage 48, 564-584. doi: 10.1016/j.neuroimage.2009.06.009

Wagner, D. D., Haxby, J. V., and Heatherton, T. F. (2012). The representation of self and person knowledge in the medial prefrontal cortex. Wiley Interdiscip. Rev. Cogn. Sci. 3, 451-470. doi: 10.1002/Wcs. 1183

Williams, R. R. (1997). Hegel's Ethics of Recognition. Berkeley, CA: University of California Press.

Received: 16 December 2013; accepted: 07 January 2014; published online: 24 January 2014
Citation: Marchetti I and Koster EHW (2014) Brain and intersubjectivity: a Hegelian hypothesis on the selfother neurodynamics. Front. Hum. Neurosci. 8:11. doi: 10.3389/fnhum.2014.00011

This article was submitted to the journal Frontiers in Human Neuroscience.

Copyright (c) 2014 Marchetti and Koster. This is an open-access article distributed under the terms of the Creative Commons Attribution License (CC BY). The use, distribution or reproduction in other forums is permitted, provided the original author(s) or licensor are credited and that the original publication in this journal is cited, in accordance with accepted academic practice. No use, distribution or reproduction is permitted which does not comply with these terms. 